\title{
EL DINOSAURIO Y LA NORMA: EL CANON COMO FICCIÓN REGULATIVA EN LA HISTORIA DE LA FILOSOFÍA OCCIDENTAL
}

\author{
Iván de los Ríos ${ }^{1}$ \\ Universidad Autónoma de Madrid
}

Recibido: 13.12.2019 - Aceptado: 10.03.2020

"Nada hay que sea inofensivo"

T.W. Adorno, Minima moralia

\begin{abstract}
RESUMEN
Una asunción habitual en el estudio de la filosofía es la de la existencia de un cuerpo selecto de pensadores y textos clásicos que contendrían los hitos fundamentales de la historia del pensamiento filosófico. A tal cuerpo se lo ha llamado "canon" y se le han atribuido virtudes y facultades modélicas. En relación con este concepto, no obstante, pueden plantearse una serie de problemas que trataremos de explicitar en estas páginas: i) ¿Existe realmente el canon de la filosofía? ii) De existir, ¿qué función cumple?, ¿cómo se constituye?, ¿es estable? iii) ¿Qué condiciones ha de cumplir un texto o un autor para entrar a formar parte del canon y en virtud de qué criterios? ¿Son criterios ideológicamente orientados o responden a valores de originalidad, sublimidad, profundidad y representatividad intrínsecos a la propia filosofía? iv) ¿Es esencial en el estudio de la filosofía la relación con el canon?
\end{abstract}

Palabras clave: canon; historia de la filosofía; enseñanza de la filosofía

\begin{abstract}
A common assumption in the study of philosophy is the existence of a list of thinkers, texts and classic topics which would contains the fundamental highlights in the history of philosophical thinking. This list has been called "canon" and is very often characterized by its model character. In connection with it, there is a number of interesting and deeply philosophical questions: i) Is there really a philosophical canon? ii) If there is: what is its function? How is it configured? Is it stable? iii) What are the requirements that a text or an author must satisfy in order to become a member of the canon and what are the criteria to select them? Are these criteria ideologically oriented or they rather respect the values of originality, sublimity, depth and intrinsic representativeness to philosophy? iv) Is it essential to the study of philosophy the reference to a canon?
\end{abstract}

Keywords: canon; history of philosophy; philosophy teaching

1 ivan.delosrios@uam.es 
1.

Si de canon se trata, empecemos con uno de los dos o tres momentos estelares en la historia de la literatura ínfima. En un microrrelato aparentemente inofensivo, el escritor guatemalteco Augusto Monterroso afirma:

Cuando despertó, el dinosaurio todavía estaba allí. (Monterroso 1959, 71)

¡Qué grande, Monterroso! ¡Qué inmenso el dinosaurio y qué minúsculo el durmiente que apenas despierta! Las interpretaciones se amontonan desde antiguo, pero parece sencillo entender el significado elemental de este puñado de letras. Monterroso está hablando del canon: del canon de Occidente en general y del canon filosófico en particular. Cuando despertó, el canon seguía allí. Ayer, hoy y siempre, cada día y en cada época, en cada círculo académico y en toda situación hermenéutica, el canon siempre ha estado allí, velando nuestro sueño y mirándonos dormir. Perdonen la broma. Nada menos canónico que recurrir a un escritor para hablar de filosofía, sobre todo si es guatemalteco y bajito y le gusta pensar en dosis mínimas de inmensidad variable. Perdonen la broma, insisto, pero no la ignoren. No descarten canónicamente este gesto lúdico e inquietante porque en esa imagen casi infantil se cifra la hipótesis central de este trabajo. Es que el canon filosófico se asemeja peligrosamente al dinosaurio más célebre la literatura universal. Un viejo reptil, un animal portentoso de autoridad irrevocable que durante siglos gobernó el planeta como un coloso. Un saurio que porta en su mismo nombre un adjetivo tan célebre como el stásimon sofocleo que lo vehicula: "pollà tà deinà koudèn anthrópou deinóteron péllei" (Antígona, vv. 332375). Muchas son las cosas terribles (deiná) que caminan sobre la faz de la tierra (y la tierra es texto, la historia, la filosofía), pero nada más terrible que el hombre ... y sus cánones. Nada más terrible que el canon. Adjetivo trágico que, sin embargo, no solo menta el temor y el horror feroz, sino también la belleza y la maravilla. Nada más portentoso, maravilloso y terrible que el canon filosófico de Occidente, que contempla, organiza y gobierna con ojo avizor y mano firme la selva histórica de la filosofía. Sin embargo, aún hay más: el dinosaurio de Monterroso no solo es un portento sublime. Es también un sueño. El contenido de un sueño. Una pesadilla, quizás. Una presencia onírica y fantasmal cuya influencia esperamos ver disipada cada mañana 
cuando abrimos los párpados. El canon es una fábula nocturna y un sueño atragantado, una obsesión del infante culpable de su minoría de edad que, sin embargo, persiste más allá de todo descanso. Una fábula terrible y maravillosa que insiste en su presencia radical e innegable.

Como el iguanodonte del guatemalteco, el canon es más real que todos nosotros y nos precede, nos vela, nos espera.

\section{2.}

Una asunción habitual en el estudio de la filosofía es la de la existencia de un cuerpo selecto de pensadores y textos clásicos que contendrían los hitos fundamentales de la historia del pensamiento filosófico. A tal cuerpo se lo ha llamado "canon" y se le han atribuido virtudes y facultades modélicas. ${ }^{2}$ En relación a este concepto, no obstante, pueden plantearse una serie de problemas que trataremos de explicitar en estas páginas:

i) ¿Existe realmente el canon de la filosofía?

ii) De existir, ¿qué función cumple?, ¿cómo se constituye?, ¿es estable?

iii) ¿Qué condiciones ha de cumplir un texto o un autor para entrar a formar parte del canon y en virtud de qué criterios? ¿Son criterios ideológicamente orientados o responden a valores de originalidad, sublimidad, profundidad y representatividad intrínsecos a la propia filosofía?

iv) ¿Es esencial al estudio o a el ejercicio de la filosofía la remisión a un canon?

En la famosa obertura de El mito de Sísifo, con un estilo contundente y marcadamente altivo, Albert Camus afirma que no existe más que un problema auténticamente filosófico: el suicidio. La interrogación por el valor de la propia existencia sería el primero entre todos los interrogantes, la pregunta fundamental a la que uno debe responder y la primera, ante todo, de cuya respuesta uno debe hacerse responsable: "No hay más que un problema filosófico verdaderamente serio: el suicidio. Juzgar si la vida vale o no vale la pena de vivirla es responder a la pregunta fundamental de la filosofía. Las demás, si el mundo tiene tres dimensiones, si el espíritu tiene nueve o doce categorías, vienen a continuación. Se trata de juegos; primeramente

2 En su célebre y polémico estudio sobre el canon literario de Occidente, Harold Bloom reconoce que la manera "más estúpida de defender el canon occidental consiste en insistir en que encarna las siete virtudes morales que componen nuestra supuesta gama de valores normativos y principios democráticos" $(1995,39)$. 
hay que responder" $(1998,15)$. En lo que sigue, y no sin cierta audacia italocalviniana, me atreveré a sugerir que, si el primer problema verdaderamente filosófico es el suicidio y el juicio sobre el valor de la propia existencia, el segundo es sin duda el canon. El canon y la norma en la (historia de la) filosofía occidental. Con permiso del suicidio, el canon es el problema central de la filosofía y de su historia porque incluye en sí mismo y en su recorrido, en su condición problemática y en sus múltiples génesis y muertes varias, algunas preguntas elementales que apelan a los fundamentos y al sentido último del ejercicio filosófico. En efecto, abordar teóricamente el canon filosófico y su rol en la historia de las ideas supone enfrentarse con preguntas de hondo calado que afectan a la naturaleza misma de la filosofía, a las condiciones (no solo filosóficas) de su formación como cuerpo de conocimientos $\mathrm{y}$ al lugar que dicho cuerpo ocupa en el horizonte educativo del pasado, el presente y el futuro de nuestras escuelas y universidades. El canon existe. El dinosaurio, en efecto, siempre estuvo allí. Aceptamos su presencia en la Academia de las Ciencias y aplaudimos su grandeza mientras maldecimos su ambigüedad y prolongamos su existencia en nuestras guías docentes. Le rendimos pleitesía, incluso (y este no es un detalle menor), en cada una de las imágenes, grabados, fotos, pinturas y esculturas que adornan los pasillos, las bibliotecas y las paredes de nuestros despachos y salas de clase. El canon existe. El canon vive, de eso no cabe duda. Reconocemos su peso y su función como un "hecho normativo flexible" (Westphal 1993, 436-449) que, si bien puede variar a lo largo de la historia en diferentes contextos sociológicos y académicos, se impone universalmente como un dispositivo de formación, enseñanza y selección en el seno de la disciplina y la profesión filosófica. De hecho, las pruebas que permiten a los ciudadanos cursar estudios de Filosofía en una universidad pública española, por ejemplo, ya demuestran la existencia, la importancia y el poder político del canon: una lista oficial diseñada por las instituciones pertinentes con el asesoramiento y ayuda de reputados especialistas en el campo de la Filosofía. Expertos que, en cuanto tales, ostentan una autoridad incuestionable acerca de cómo debe hacerse, leerse y practicarse este viejo oficio del pensar y que, pese de sus distintas biografías intelectuales, acuerdan e imponen institucionalmente aquello que debe estudiarse y saberse en marcos educativos preuniversitarios y universitarios. Aquello que -al menos- debe saber un aspirante a Graduado, Doctor o Profesor es el corazón mismo en torno al cual se articula el desenvolvimiento de la filosofía en Occidente. Una venerable serie de obras, autores y temas indispensables en la historia del pensamiento occidental sin cuya presencia podría tambalearse el edificio entero de la Razón: Platón y la teoría de las ideas; Aristóteles y el problema de la sustancia; San Agustín y el problema 
de Dios; Santo Tomás: metafísica y teología; Descartes y la doctrina del cogito; Hume y el fenomenismo moderno; Rousseau y el contrato social; Kant y los límites del conocimiento; Hegel y la ciencia de la experiencia de la conciencia, Nietzsche y el superhombre... Se trata de un mero ejemplo entre los muchos posibles, pero este ejemplo, este listado escuálido y estandarizado que se impone institucionalmente en las escuelas como un dispositivo de formación y, por tanto, como un mecanismo de inclusión o exclusión, expresa a la perfección la afirmación un tanto exagerada que hemos realizado al comienzo: el canon es el segundo problema fundamental de la filosofía. Es que ese listado, cualquier listado, cualquier malla universitaria o currículo de estudios nos confronta con un puñado de preguntas incómodas que desembocan directamente en el interrogante por la naturaleza, los límites y las condiciones de formación de la filosofía y por las relaciones entre la historia canónica de la filosofía y sus exclusiones selectivas. Por ejemplo: ¿Dónde están los presocráticos y los socráticos menores? ¿Dónde están los cínicos con su insolencia, los cirenaicos con sus placeres, los epicúreos y escépticos con sus modelos negativos de ataraxía y ágnoia como ideal de vida? ¿Hiparco, Anaxarco? ¿Dónde está Antifonte y su arte para combatir la tristeza? ¿Hipócrates? ¿Galeno, Filebo, Eudoxio, Pródico? ¿Dónde están Artemidoro, Filón, Sinesio o Sofronio y sus relatos sobre las imágenes nocturnas, el sueño y la oniromancia? ¿O es que es que el sueño no es un asunto digno del pensar filosófico? ¿Los son los mitos, el amor, los mapas, el sexo, el dolor, el humor, la cárcel, el cine o las representaciones médicas del cuerpo humano? ¿Dónde están Damascio y Olimpiodoro? ¿Dónde está Hipatia? ¿Y los gnósticos? ¿Por qué no aparecen Basílides, Carpócrates o Valentín en los programas universitarios? ¿Dónde están Amaury de Bène y Willem Cornelislz? ¿Por qué nunca hemos oído hablar de ellos? ¿Dónde están Lorenzo Valla, Ficino y Erasmo? ¿Dónde está Montaigne? ¿Y Pascal? ¿Dónde están Charron, SaintÉvremond y Pierre Gassendi? ¿Dónde está Sade? ¿Y las mujeres? ¿Acaso no hubo mujeres filósofas? ¿Acaso es que esos "niños grandes", como sugería el buen Kant, no tuvieron pulsión teórica alguna o su exclusión y escasa presencia en la historia de la filosofía responden a entramados más complejos? ¿Por qué no estudiamos Sobre la igualdad de hombres y mujeres de Marie Le Jars de Gournay? ¿Por qué no sabemos quiénes fueron o qué escribieron Olympe de Gouges, Hedwig Dohm, Anne Finch Conway o Harriet Taylor Mill? ¿Por qué ya no leemos a Rosa Luxemburgo en nuestras historias de la filosofía contemporánea?

Responder a estas preguntas es relativamente sencillo: el ser humano es finito y carece del tiempo necesario para leer, asimilar y clasificar como 
es debido sus múltiples saberes. Tantas bibliotecas y tan poco tiempo: "Poseemos el canon porque somos mortales y nuestro tiempo es limitado" (Bloom 1995, 40). Sin duda, pero lo cierto es que el propio Bloom insiste una y otra vez en que la lista de autores y obras que a su juicio componen el canon literario occidental no responde sin más a las inclemencias de la finitud. No se trata de un problema meramente cuantitativo ni de una opción cualquiera entre las muchas posibles: "La selección no es tan arbitraria como pueda parecer. Los autores han sido elegidos tanto por su sublimidad como por su naturaleza representativa" (Bloom 1995, 12). Existe, a juicio de Bloom, un horizonte de valores intrínsecos a las obras que forman parte del canon: valores estéticos de originalidad, sublimidad o representatividad que justifican la presencia de ciertos escritores (y la ausencia de otros muchos más) en virtud de criterios puramente estéticos. Este conjunto de valores permite, por sí mismo, rechazar con firmeza cualquier interpretación ideológica procedente de los ignorantes y advenedizos miembros de la "Escuela del Resentimiento" (Bloom 1995, 35): "Nada resulta tan esencial al canon occidental como sus principios de selectividad, que son elitistas sólo en la medida en que se fundan en criterios meramente artísticos. Aquellos que se oponen al canon insisten en que en la formación del canon siempre hay una ideología de por medio; de hecho, van más allá y hablan de la ideología de la formación del canon, sugiriendo que construir un canon (o perpetuar uno ya existente) es un acto ideológico en sí mismo" (Bloom 1995, 32). Más adelante tendremos ocasión de discutir las afirmaciones de Bloom. Por el momento, y pese a las diferencias que separan el canon literario del filosófico en la tradición occidental, parece que estas reflexiones nos sitúan ante una nueva serie de preguntas incómodas que, en este caso, avanzan hacia un plano más profundo de intensidad filosófica. Si el canon existe, si es un hecho normativo y flexible, si existe una norma o patrón para el estudio y la enseñanza de la historia de la filosofía, si su naturaleza es selectiva y limitada dada la brevedad de la vida y la longitud de la ciencia, entonces cabe preguntarse por las condiciones de formación del canon y la norma filosófica en cuya corriente seguimos navegando. Si el canon existe hemos de preguntar, en efecto, cómo es que existe y por qué. Además, si pudiéramos responder a esas preguntas, entonces habríamos respondido también a estas otras: ¿qué es y qué no es filosofía? ¿Qué es y qué no es un problema filosófico? ¿Qué debe contener un discurso, un relato, cualquier forma organizada de expresión significativa para ser clasificada dentro del universo de la filosofía? ¿Y qué sería un filósofo? ¿Aquél que escribe de manera más o menos sesuda, profunda, radical e inteligente sobre problemas clasificados previamente como filosóficos? ¿O es al revés? ¿Los profesores universitarios son filóso- 
fos? ¿Los profesores de filosofía en la secundaria son filósofos? ¿Existen filósofos fuera de la academia? Y en todo caso, ¿quién cartografía y rotura los límites del objeto filosófico en general y del canon de autores y obras en particular? ¿La tradición? ¿El poder? ¿El azar? ¿Desde qué instancias normativas se establecen los criterios para incluir o excluir de un sistema canónico y regulador determinadas obras y autores? Además, una vez cartografiado el terreno, una vez que hemos aceptado más o menos a regañadientes que existe un perímetro oficial de la temática y la producción filosófica, ¿quiénes ocuparán los puestos más altos de la clasificación? ¿Qué entidades ostentan el grado supremo de la jerarquía y por qué? ¿Qué tienen Platón, Kant o Aristóteles que no tengan Berkeley, Arendt, Marquard o Schopenhauer? Es más: ¿qué tiene el Sofista que no tenga el Gorgias? ¿Por qué República y no Cármides? ¿Por qué la Metafísica y no los deliciosos escritos sobre la vejez, el sueño y la muerte incluidos en Parva naturalia? En definitiva: ¿qué es lo que enseñamos en nuestras escuelas de Filosofía y por qué? 0 mejor: ¿qué es lo que no enseñamos y por qué?

3.

Como puede verse, el asunto que tenemos entre manos se parece peligrosamente a un buen diálogo platónico. A la República, por ejemplo, donde, partiendo de una pregunta aparentemente simple (¿qué es la justicia?), se nos muestra caleidoscópicamente la naturaleza integral del trabajo filosófico, la trenza inevitable entre las dimensiones de la metafísica, la epistemología, la ética, la religión, la política, la estética y la psicología. La pregunta por el canon goza de una similar potencia de apertura. La inquietud por su condición, su formación, su historia o su pregnancia parece llamar a otras preguntas no menos inquietantes como la de las relaciones de la filosofía con su historia o la delimitación conceptual de un perímetro temático exclusivamente filosófico. No obstante, más allá de la perplejidad y fascinación intrínsecas que nos produce toda cuestión relativa a los fundamentos de aquello que nos sostiene en el interior de una historiografía, el problema del canon debe ser abordado con cierto orden, con cierta voluntad de sencillez y sin complejos. En este sentido, quizás sea útil formular una serie de preguntas más o menos simples: i) ¿de qué estamos hablando y de qué no estamos hablando cuando nos referimos al canon filosófico de Occidente?; ii) ¿cuáles han sido y, quizás, siguen siendo las respuestas más extremas al problema del canon y en qué medida son todavía aceptables?; y, por último, iii) ¿cuál sería relación más fértil, más inteligente y menos arriesgada que las comunidades filosóficas en toda su complejidad podrían o deberían establecer con el canon? Comencemos por la primera: 


\section{a) ¿De qué estamos hablando al hablar de canon filosófico?}

El canon de la filosofía no es un asunto meramente histórico ni se identifica sin más con la historia de la filosofía. No obstante, su esclarecimiento pasa necesariamente por una reflexión de fondo sobre la condición histórica de todo filosofar, por la naturaleza especulativa de la historia misma y por el sentido no siempre explícito de los procesos de inclusión y exclusión que jalonan la formación de dicho canon. Como ha sugerido Richard Schacht, a menudo se tiene la impresión de que el canon filosófico no es un asunto relevante ni particularmente presente en las discusiones filosóficas, o que al menos no lo es al nivel en que dicha discusión se produce en otras disciplinas. Sin embargo, esa impresión bien pudiera deberse a que, en toda discusión filosófica, el debate sobre el canon está implícito de manera más o menos evidente (Schacht 1993, 421). Quienes hoy escribimos, leemos o enseñamos filosofía seguimos siendo herederos de un gesto crucial que, paradójicamente, ha convertido la reflexión filosófica sobre la historia de la filosofía en un tema relevante para nuestros intereses teóricos y académicos. ${ }^{3}$ Ese gesto crucial es, precisamente, el que, en los albores del siglo XX y bajo diversas etiquetas, aspiró a la habilitación de un perímetro aislado de invulnerabilidad y autofundamentación para la razón teórica: un espacio de acción blindado contra toda forma de accidentalidad, contingencia, temporalidad e historia. Como ha recordado Jim Jakobson, en ese gesto podemos reconocer algunas tendencias fundamentales de la filosofía temprana del siglo XX: "A marked tendency in early 20th century philosophy was to leave the concern with earlier philosophy to historians and instead try to establish a presuppositionless knowledge with the help of new-found philosophical tools: logico-linguistic analysis and/or phenomenological research into essences" (Jakobson 2005, 55).

Frente a esta tendencia, la discusión sobre el canon nos permite avanzar más allá de los deseos del análisis filosófico o de la investigación fenomenológica e introducirnos en la historia de la filosofía cada vez que pensamos filosóficamente. No obstante, es importante recordar que la perspectiva introducida por el canon en filosofía no es, como decíamos, idéntica a la perspectiva histórica sobre el pasado de la propia filosofía, sobre sus autores, sus máximos representantes y sus obras magnas. En efecto, la perspectiva canónica no solo se extiende hacia el pasado como un relato retrospectivo o un informe, sino que se abre hacia el futuro de la educación en filosofía y, por

${ }^{3}$ Para una visión panorámica sobre el debate de los últimos años, puede consultarse el artículo de María Cristina González y Nora Stigol, "La filosofía y su historia. Un debate abierto", Revista de Filosofía", 2012, 151-170. 
ende, hacia el destino de nuestras escuelas y saberes en el ámbito especializado. Como recordaba Westphal, el canon es un hecho incuestionable, pero sobre todo es un hecho normativo y normalizador, lo que lo convierte en un asunto ético-político de primer orden. Si esto es así, parece importante delimitar con precisión a qué nos estamos refiriendo.

En un trabajo conciso y clarificador, Silvia Manzo ha tratado de arrojar un poco de luz sobre esta pregunta y de distinguir algunos de los rasgos que, por lo general, caracterizan al canon filosófico en sus diversas expresiones (2017). La referencia más intuitiva cuando pensamos en el canon en sentido general es, sin duda, el ámbito eclesiástico. En sede eclesiástica, el canon puede entenderse como una la lista definitiva de libros que, según acuerdan las autoridades pertinentes, han sido inspirados por Dios a uno o a varios hombres. La autoridad del canon se basaría, entonces, en el supuesto de que Dios ha transmitido su Palabra por medio de seres humanos que hablaron inspirados por Él. Esa palabra debe, por tanto, ser escuchada, respetada, venerada y obedecida. La analogía eclesiástica es tremendamente fértil para nuestros intereses. En efecto, el canon es, ante todo, la norma: la regla de vida. Un sentido que ya está presente desde el origen mismo del término griego (kanón) y que aparece recogido, por ejemplo, en las reflexiones aristotélicas sobre el hombre virtuoso, que es regla y medida de lo bueno (hósper kanòn kaì métron). ${ }^{4}$ El canon es, entonces, un conjunto de libros tenidos por referenciales y reconocidos como autoridades en un horizonte filosófico parcial (el canon de la filosofía moderna, por ejemplo, que es el que más interesa a $\mathrm{Manzo}^{5}$ ) o en el horizonte de la filosofía en general:

Por eso, hay cánones más generales -como el canon de la filosofía occidentalo cánones con distintos tipos de especificidad, sea por sus áreas temáticas -como el canon de la estética-, por el periodo que abarcan -como el de la filosofía moderna o del Renacimiento-, por la corriente filosófica a la que pertenecen -como el canon del empirismo o del racionalismo-, o por la pertenencia a un territorio o nación como el canon de la filosofía argentina o alemana-, etc. Este sentido de canon, por extensión, suele tener una connotación de norma, precepto o regla, en la medida en que la lista de obras o autores es juzgada como necesaria para alcanzar un conocimiento o dominio de la filosofía. Está ligado con la formación de los filósofos en el marco de una institución de enseñanza. $(2017,117)^{6}$

\footnotetext{
${ }^{4}$ Aristóteles, Ética a Nicómaco III 4 1113a33.

${ }^{5}$ Manzo recoge, para distanciarse de ellas, otras definiciones del canon como la de Eduardo Rabossi, para quien todo canon es la "preceptiva básica que estipula y define el dominio, los supuestos teóricos y prácticos, las metas, los objetivos y los valores que les son propios [a una profesión]" $(2008,73)$. En este punto seguimos a Manzo y no nos adentramos en el planteamiento de Rabossi, que puede, no obstante, ser muy fructífero.

${ }^{6}$ Un estudio espléndido sobre este último sentido del canon señalado por Manzo es el de José Luis Moreno Pestaña, La norma de la filosofía. La configuración del patrón filosófico español tras la Guerra Civil (2013).
} 
Esta noción clásica del canon viene asociada, además, a la formación de las universidades europeas y, como tal, se expresa nítidamente en los programas, las guías docentes y los curricula universitarios. En efecto, si bien es posible "constatar la presencia de cánones de la filosofía ya en la universidad medieval y luego en las etapas renacentista y moderna, su impacto más notable tuvo lugar cuando la filosofía se profesionalizó como una disciplina autónoma en la universidad contemporánea a comienzos del siglo XIX en Europa y en las primeras décadas del siglo XX en Argentina. En tales circunstancias, los cánones de la filosofía se cristalizaron de manera creciente en la medida en que la filosofía misma se iba recortando como una disciplina más entre otras en el espectro disciplinar universitario" (Manzo 2017, 119).

La imbricación del canon en el sentido descrito y operativo en nuestras universidades implica un segundo rasgo relevante desde el punto de vista de la claridad conceptual: el canon emerge, opera y pervive ligado a las instituciones de enseñanza y, por tanto, es siempre y necesariamente colectivo:

Sea cual sea la actitud frente a las relaciones de poder implicadas en la institución y los objetivos del profesor, el canon fija un punto de partida cumpliendo la función de transmisión del conocimiento asumida por la institución de la cual acepta formar parte. De este modo, cuando hablamos de canon no pensamos en la lista que un profesor elige para sí mismo, sino en un catálogo compartido por un colectivo de filósofos profesionales a ser transmitido a otro colectivo que aspira a serlo. (Manzo 2017, 120)

El canon es colectivo, pero no universal. En efecto, la dimensión del poder institucional resaltada por Manzo (quien se inspira en la obra de europeos célebres como Pierre Bourdieu y Michel Foucault, pero también de americanos atentos al problema del canon en Latinoamérica como Jorge Gracia $^{7}$ ) implica un margen de referencia geopolítico y cultural que también condiciona los contenidos del canon dependiendo de naciones y latitudes. En todo caso, nos importa resaltar que el listado venerable de autores y obras que componen los cánones filosóficos en su diversidad es siempre un listado producido y propagado desde instituciones educativas superiores y que se trata de un listado refrendado por la autoridad de un colectivo especializado reconocido entre sus pares. En este sentido, y por contraste con el canon eclesiástico, la autoridad del canon no deriva de una instancia trascendente que exige obediencia ciega, sino que se configura históricamente en un plano de fuerzas en el que se cruzan dinámicamente individuos e instituciones. Es precisamente esa condición contingente del canon lo que con-

7 Jorge Gracia “Cánones filosóficos y tradiciones filosóficas: El caso de la filosofía latinoamericana”, Análisis filosófico, vol. XXX, № 1 (2010): 117-34. 
duce a Manzo a destacar una tercera característica, que ya hemos mencionado con anterioridad. Dada la trenza entre el conjunto de individuos históricos y las instituciones de poder teórico que los vehiculan, el canon se convierte necesariamente en un hecho normativo de inclusión y exclusión que dispone, organiza y ordena qué autores y obras han de ser estudiados en un determinado contexto geográfico y cultural para entrar a formar parte de la comunidad de profesionales del saber filosófico:

Directa consecuencia de lo anterior es otro rasgo esencial del canon, a saber, el hecho de que es excluyente, ya que deja afuera una gran cantidad de autores y textos, y también de temas y subtemas filosóficos. Hay quienes cargan esta característica con un valor negativo al considerarlo como represiva. Sin embargo, la exclusión en sí no es ni positiva ni negativa, dado que es inherente al canon. En todo caso, lo que es pasible de ser calificado como bueno o malo, lo que puede merecer un juicio de valor, es algo anterior a la inevitable exclusión canónica: la decisión de enseñar filosofía y formar profesionales de acuerdo a las determinaciones exigidas por una institución de enseñanza. Una vez tomada la decisión, si aceptamos lo primero, lo segundo -la selección y la consiguiente exclusión canónica- es inevitable. El canon, por lo tanto, es tan represivo como lo es cualquier institución social. (Manzo 2017, 123)

Hasta aquí la aproximación de Silvia Manzo. Si asumimos lo expuesto por la profesora argentina, podemos decir, entonces, que existe un sentido habitual del término canon que remite a una tradición universitaria concreta y que nos habla de un conjunto de obras y autores pertenecientes a la historia tratados institucionalmente como instancias referenciales, venerables y, en todo caso, absolutamente necesarias para determinar las capacidades de un individuo para dedicarse profesionalmente a la docencia y a la investigación filosófica. Las reflexiones de Manzo son importantes porque nos obligan a reformular, con más vehemencia si cabe, algunas preguntas que planteábamos al comienzo de este escrito. Parece claro, en efecto, que existe un relato canónico aplicable al ámbito de la academia europea y, por extensión, latinoamericana. ${ }^{8}$ ¿Quién aceptaría un canon filosófico en el que Platón, Aristóteles, Descartes o Kant estuvieran completamente ausentes? ¿Acaso no estamos de acuerdo en que ciertos autores y ciertas obras son inevitables en Filosofía y que siempre estarán allí cuando despertemos de nuestros ya no

${ }^{8}$ Sobre el problema del canon en Latinoamérica y sus relaciones con Europa, véase el artículo ya mencionado de Jorge Gracia, "Cánones filosóficos..." y algunas otras de sus obras: Jorge Gracia (ed.), Latin-American Philosophy in the Twentieth Century: Man, Values and the Search for Philosophical Identity (Buffalo, NY: Prometheus Books, 1986); Philosophy and Its History: Issues in Philosophical Historiography (Albany, NY: State University of New York Press, 1992); Hispanics, Philosophy and the Curriculum", Teaching Philosophy vol. 22, № 3 (1999), 241-248. 
tan dogmáticos sueños? Sin duda, pero: ¿por qué están allí? ¿Qué los convierte en merecedores de tamaña gesta? ¿Cuál es la fuente de legitimidad del dinosaurio y su norma?

\section{b) El enfoque purista y el mito anticanónico: dos respuestas extre- mas al problema del canon}

Ante esta pregunta caben al menos dos respuestas igualmente extremas y, por tanto, rechazables. La primera estaría caracterizada por lo que podríamos llamar el "enfoque purista". La aproximación purista al canon filosófico tendría una clara forma de responder al porqué de la presencia de los autores consagrados en los listados canónicos. Aquello que haría actual, relevante, inevitable y eternamente presente a un autor o a una obra, aquello que nos permitiría, como sugiere Moreno Pestaña, ${ }^{9}$ encontrar en sus textos un valor intelectual imperecedero, un placer estético sublime y una orientación moral y política absolutamente confiable, sería el valor intrínseco que contienen los textos auténticamente filosóficos, independientemente del momento histórico en que hayan sido escritos, de las circunstancias biográficas de sus autores y de los condicionamientos externos que rodeen a la propia obra. En otras palabras, y de acuerdo con cierto ideal cognitivo antinaturalista que hemos recordado al hilo de las tendencias filosóficas de la filosofía analítica y de la fenomenología, la filosofía sería concebida como una disciplina autónoma basada en una razón autofundamentadora y blindada epistémicamente contra toda forma de saber externo (sociología, antropología, biología, economía, etc.) y contra toda contingencia histórica más allá de los argumentos que articulan y atraviesan las obras mismas. Mutatis mutandis, ese parece ser también el argumento de Bloom en relación con el canon literario, articulado en torno a la negación y rechazo de todo elemento que pueda contaminar el valor estético intrínseco a las figuras canónicas:

Ningún movimiento originado en el interior de la tradición puede ser ideológico ni ponerse al servicio de ningún objetivo social, por moralmente admirable que sea éste. Uno solo irrumpe en el canon por fuerza estética, que se compone primordialmente de la siguiente amalgama: dominio del lenguaje metafórico, originalidad, poder cognitivo, sabiduría y exuberancia en la dicción. (Bloom 1995, 39)

Volvamos al terreno de la filosofía. ¿Qué habría llevado a las obras filosóficas y a sus autores a irrumpir en el canon de Occidente? ¿La fuerza filosófica, quizás? ¿De qué se compondría esta fuerza primordialmente? Suponemos que nuestra fuerza compartiría con la fuerza literaria al menos la

${ }_{9}^{9}$ Moreno Pestaña 2013, 17. 
originalidad, el poder cognitivo y la sabiduría, aunque parece menos claro el juicio sobre el dominio de la metáfora y la exuberante dicción, si atendemos el tratamiento que ciertos filósofos (tan canónicos, por cierto, como Descartes y Locke) le han dado a toda forma de lenguaje traslaticio. Frente al dominio del lenguaje metafórico y la exuberancia poética, quizás la fuerza filosófica estribaría en la claridad conceptual, la solidez argumental, la inteligibilidad o el perfecto encadenamiento entre premisas y conclusiones. Claridad, solidez, inteligibilidad y autosuficiencia argumentativa, cualidades todas que parecen coincidir perfectamente con el valor que el viejo Spinoza atribuye a los textos matemáticos y propiamente filosóficos en el capítulo VII de su Tratado teológico-político. Un texto en el que Spinoza ensaya un modelo externo de lectura para los textos sagrados, que se encuentra en estricta oposición con la lectura interna propiamente matemática y filosófica. Esa lectura no debe atender a otros elementos que a los que aparecen con suprema inteligibilidad en el interior de un texto dado, tal y como ocurre al leer los Elementos de Euclides:

Euclides, que no escribió más que cosas muy simples y sumamente inteligibles, cualquiera lo puede explicar fácilmente en cualquier lengua. Puesto que, para captar su pensamiento y estar ciertos de su verdadero sentido, no es necesario tener un conocimiento completo de la lengua en la que escribió, sino muy ordinario y casi infantil; no es necesario conocer la vida, ni las aficiones ni las costumbres del autor; ni en qué lengua escribió, para quién y cuándo; ni los avatares del libro ni sus diversas lecturas, ni cómo ni quiénes aconsejaron aceptarlo. Y lo que aquí decimos de Euclides, hay que decirlo también de todos los que escribieron sobre cosas perceptibles por su naturaleza. (Spinoza 1986, 211)

El caso de las Escrituras le parece bien distinto al pulidor de lentes. A diferencia de lo que ocurre con los textos matemáticos o propiamente filosóficos, comprender las sagradas Escrituras significa ante todo comprender su historia: "De ahí que la regla universal para interpretar la Escritura es no atribuirle, como enseñanza suya, nada que no hayamos constatado plenamente por su historia" (Spinoza 1986, 195). Para comprender esa historia, afirma Spinoza, es necesario atender a varios factores: i) la lengua y el horizonte simbólico al que pertenecen las expresiones empleadas por los autores: la historia de la Escritura debe "contener la naturaleza y propiedades de la lengua en la que fueron escritos los libros de la Escritura y que solían hablar sus autores. Pues así podremos investigar todos los sentidos que, según el modo habitual de hablar, puede admitir cada oración" (Spinoza 1986, 195); ii) la vida y circunstancias del autor de cada uno de los libros: "La historia de la Escritura debe describir, finalmente, los avatares de todos los profetas, de los que conservamos algún recuerdo, a saber: la vida, las costumbres y gustos del autor de cada libro; quién fue, con qué ocasión, en qué 
época, para quién y, finalmente, en qué lengua escribió. Debe contar además los avatares de cada libro: primero, cómo fue aceptado y en qué manos cayó; después, cuántas fueron sus diversas lecturas y quiénes aconsejaron aceptarlo entre los libros sagrados; cómo, finalmente, todos los libros, una vez que todos los reconocieron como sagrados, llegaron a formar un solo cuerpo" (Spinoza 1986, 196-7).

En su libro sobre el canon filosófico español después de la Guerra Civil, Moreno Pestaña destaca las posibilidades que el modelo spinoziano ofrece a toda interpretación no purista (¿impura?) del canon y de la historia misma de la filosofía. En efecto, "Spinoza nos invita a un conjunto claro de operaciones de investigación, sin duda productivas para la sociología de la filosofía: estudio de la experiencia social de los productores, de los universos simbólicos en los que debieron expresarse, de los efectos de la conversión de un producto cultural en un bien simbólico de un campo intelectual" (Moreno Pestaña 2013, 19).

Una lectura purista de la historia de la Filosofía y del canon filosófico mismo supondría, entonces, una aproximación exclusivamente interna a los textos consagrados en la que la lengua y el consiguiente universo simbólico en que esta se desenvuelve son tan irrelevantes como las circunstancias del autor o autora, su situación vital y sus intereses, o como el procedimiento de formación de un corpus en el tiempo mediado por la recepción e interpretación de los receptores. En este sentido, y llevando el modelo hermenéutico al orden del canon, parece posible pensar que las propiedades que permitirían a un texto irrumpir en un canon determinado serían propiedades esenciales al texto mismo, interpretado este al margen de las condiciones externas de su formación, los avatares de su transmisión y los ámbitos de relacionalidad y el universo de propiedades relacionales que con ellos se abren.

En el otro extremo del enfoque purista encontramos lo que, siguiendo a Bloom, podríamos denominar "el mito anticanónico" (Bloom 1996, 50) de la Escuela del Resentimiento. Una escuela que, en nombre de la dimensión histórica de los problemas filosóficos, la representatividad, la justicia social, la deconstrucción de los grandes relatos, la muerte del autor o el ensamblaje de fuerzas no conscientes, afirma no solo la inexistencia del canon per se, sino ante todo su carácter tóxico, engañador y cuasi diabólico. Esta línea de interpretación acogería, quizás, a buena parte del llamado pensamiento post-metafísico y a muchos de sus más ilustres representantes: Nietzsche, Foucault, Deleuze, Derrida, Roland Barthes y “otros autores clónicos posteriores" (Bloom 1996, 50). Ahora bien, es necesario subrayar que dichas propuestas no desembocan necesariamente en un rechazo terrorista que anima a la destrucción de todo orden canónico. Se trata, más bien, de ensayos que 
persiguen desvelar la naturaleza puramente histórica y humana, demasiado humana, esto es, contingente y nunca necesaria, eterna, trascendente, imperecedera e ignorante de los contextos situacionales de creación, transmisión y recepción de la cultura. Asimismo, y el caso de Nietzsche es en este sentido ejemplar, el problema del canon (como el del arte, por ejemplo) ya no sería enfocado en términos esencialistas. Es decir, la pregunta que interesa a esta línea no purista de interpretación no es ya “¿qué es el canon?”, sino “¿cómo el canon vigente ha devenido el canon que es?”, “¿cuál es el origen genealógico del valor sagrado del canon?". La filosofía metafísica deja paso, en efecto, al enfoque genealógico, y las perspectivas de análisis sobre el pasado (de la filosofía, del arte, de la cultura, los valores o los sentimientos morales) se enriquecen más allá del conocimiento de sus ingredientes supuestamente esenciales.

Dicho esto, también es posible, sin embargo, encontrar autores particularmente célebres (y felizmente ajenos al reconocimiento de sus pares) en nuestros días que han convertido la destrucción del canon y la necesidad de una reescritura de la historia de la Filosofía en el sentido nuclear de su producción teórica. Entre esos autores, destaca con particular vehemencia (una vehemencia que es también televisiva) el pensador francés Michel Onfray, declarado admirador del proyecto nietzscheano y, como tal, una figura intelectual que escribe con el fin de desenmascarar los diversos ídolos que, a su juicio, el platonismo y el cristianismo han insuflado en la Historia de Occidente, impidiendo con ello vivir a la altura de la temporalidad, la corporalidad, el deseo y la muerte que nos atraviesan. En un tono agresivo, ágil, punzante y, en ocasiones, irresistible, con una deliberada transgresión de las normas propias de producción contemporánea de obras y artículos científicos, Onfray entona su particular Écrasez l'infâme contra la historiografía filosófica occidental. A su juicio, buena parte de las obras y autores que siguen siendo veneradas como reliquias eclesiales responden a la victoria de una facción distinguida en el interior de esa guerra violenta, de esa polemología que vendría a ser la historia de la filosofía. En el marco de esa lucha histórica de fuerzas ideológicas entrelazadas con poderes institucionales, Onfray considera que el gran vencedor y, por tanto, el organizador del pasado, ha sido el ideal ascético denunciado por Nietzsche en su Genealogía de la Moral:

¿Cuándo, cómo y dónde, alguien -y quién- dice que está en presencia de la filosofía o de un filósofo? ¿Qué instancias visibles o invisibles legitiman el uso del epíteto y de la calidad? ¿Hay lugares, circunstancias, ocasiones, intermediarios, disposiciones, instituciones, abiertamente o no, mediante los cuales se puede determinar si una obra o un pensador remiten al santo de los santos filosóficos? ¿Cómo entrar en una historia de las ideas, en los manuales o en la época ataviado con las plumas del filósofo? Hay muchas instancias legitimantes que contribuyen a una historia 
académica. Esta tradición la hemos de identificar y hacer pedazos. (Michel Onfray $2008,35)^{10}$

No nos interesa tanto la propuesta de Onfray y su polémico lugar en la intelectualidad francesa, como el alcance de sus afirmaciones. Ante todo: la insistencia vehemente en que la historia de la filosofía occidental y sus cánones son, como todos las demás, constructos dinámicos formados a lo largo del tiempo y en cuyo modelaje influyen no solo la potencia teórica de las obras, la inteligibilidad de los contenidos, la brillantez argumentativa o la originalidad, sino también (y sobre todo) los factores externos, los contextos ideológicos e institucionales y los enclaves sociopolíticos. Los intereses inconfesables, diría el nietzscheano, que laten en el fondo de los valores supremos e intachables de la cultura occidental. La historia de la filosofía, a juicio de Onfray, es una historia escrita por el platonismo y el cristianismo y, en este sentido, es la historia de la negación, el rechazo y el desprecio de todos aquellos conceptos, experiencias y figuras que designan los aspectos coyunturales y marginales de lo real a partir de una propuesta metafísica y epistemológica centrada en las coordenadas de la inmutabilidad, la eternidad, la estabilidad y la permanencia. Esa historia es la historia oficial de la Filosofía occidental y de ella emana un canon de autores y obras como el que todavía hoy estudiamos en nuestras aulas. La presencia implica la ausencia. La inclusión, la exclusión. Los excluidos son los representantes de una tradición sepultada por los ideales ascéticos: la tradición materialista, hedonista y atea que se remonta al atomismo antiguo y llega, soterradamente, hasta nuestros días.

Si nos preguntamos ahora por el encuentro inesperado entre estas dos lecturas del canon (el enfoque purista y el mito anticanónico), veremos que, en realidad, ambas pecan de un mismo exceso. Ese exceso es la negación de la historia en sus múltiples facetas. Es negación purista de la historia contextual y de sus efectos, porque apelar a valores filosóficos intrínsecos y no relacionales independientemente de los contextos históricos, de la experiencia social de producción del pensamiento filosófico y del horizonte simbólico de su recepción, significa, simplemente, caer en el vicio más antiguo de la religión y la metafísica. Ese vicio, decía Nietzsche, no es otro que la falta de sentido histórico:

¿Me pregunta qué es idiosincrasia en todo filósofo?... Por ejemplo, su falta de sentido histórico, su odio a la representación misma del devenir, su egipticismo. Ellos creen honrar algo cuando lo deshistorizan, sub specie aeterni - cuando lo

10 Michel Onfray 2008, 35. Para captar la forma y el fondo de la propuesta de Onfray, basta leer los varios volúmenes de su Contra-historia de la filosofía (2007) y su Anti-manual de Filosofía (2005). 
convierten en una momia. Todo lo que los filósofos han manejado desde hace milenios fueron momias conceptuales; de sus manos no salió vivo nada real. Matan, disecan esos señores idólatras de los conceptos cuando adoran, - se vuelven mortalmente peligrosos para todo, cuando adoran. (Nietzsche KSA, Bd. 6, 74) ${ }^{11}$

"Demnach ist das historische Philosophieren von jetz ab nöthig und mit ihm die Tugend der Bescheidung" (Nietzsche, KSA, Bd. 2, 25) (Es necesario, en efecto, practicar de ahora en adelante la filosofía histórica y, con ella, la virtud de la modestia). La pregunta por las condiciones históricas y genealógicas de formación del sentido en sus más diversos regímenes no puede ya ser obviada más que en nombre de la defensa romántica e ingenua del genio artístico o filosófico. Un individuo tocado por la gracia, inmune al contexto que lo limita y posibilita, del que emana naturalmente, como de una cascada, la exuberancia en el estilo, la claridad lógica, la potencia cognitiva o la originalidad. Desde este punto de vista, la historia de la filosofía es un devenir más o menos violento en el que la grandeza se impone dolorosamente a sus múltiples impedimentos, dejando tras de sí toda mediocridad y configurando horizontes insulares poblados por un número selecto de autores y obras que deben ser reverenciados y catapultados hacia el futuro desde todas las instituciones de enseñanza, con el fin de que ese impulso natural a la grandeza continúe su curso sin ser entorpecido por la mediocridad y la atrofia que caracteriza a los pensadores menores.

Sin embargo, el frente anticanónico comete un error similar y niega, paradójicamente, la historia. Pues es en el interior de esa misma historia donde se van formando, donde van cristalizando paulatinamente núcleos de fuerza, historias oficiales, cánones imperantes que, pese a su posición de poder, no cierran la posibilidad del diálogo constante, la transformación, la apertura o, incluso, la muerte de la tradición. Propuestas como la de Onfray son en extremo reduccionistas y parecen obligarnos casi futbolísticamente a tomar parte por los vencedores o los vencidos, los santos o los malditos. Sin embargo, ¿es Platón un santo venerado en Occidente o más bien una plataforma conceptual, un territorio coral repleto de voces antagónicas que demuestra que la filosofía es el arte del combate articulado mediante el diálogo, el argumento y la palabra? ¿Podemos defender el canon sin caer en el egipticismo y en la negación del sentido histórico? ¿Es posible establecer qué cualidades tienen las obras que no terminan de desaparecer de nuestros programas oficiales sin caer en la idolatría? Lo es, sin duda, siempre que interpretemos el canon como una ficción regulativa en la historia de la Filosofía occidental y atendamos a sus tendencias, a sus exclusiones y a su potencia

11 La traducción es nuestra. 
configuradora desde una interpretación no metafísica de las relaciones entre sujeto y mundo, pasado y presente, escritura y lectura.

c) ¿Cuál sería relación más fértil, más inteligente y menos arriesgada que las comunidades filosóficas en toda su complejidad podrían o, incluso, deberían establecer con el canon?

Empezábamos este trabajo con una bravata lúdica, recordando el relato de Augusto Monterroso y poniéndolo a nuestro servicio para afirmar que, al igual que el dinosaurio de la literatura ínfima, el canon siempre ha estado allí. El canon existe y parece estúpido negarlo. El canon es un hecho, dijimos, pero es mucho más. Es un hecho normativo y flexible y es, además, una figura que, a diferencia del canon eclesiástico, nada tiene que ver con la ceguera, el dogma, la pleitesía, la reverencia, el sometimiento o la idolatría. Ni siquiera con el amor puro. El canon de la filosofía es un campo de batalla, un cementerio lleno de muertos y de supervivientes, un territorio poblado por autores y obras que en absoluto han terminado de decirnos todo aquello que nos pueden decir. Reconocemos el canon. Criticamos el canon. Denunciamos sus falencias, sus olvidos, sus torsiones ideológicas innegables y repugnantes cuando responden a criterios clasistas, racistas o machistas. Odiamos el canon. Lo odiamos porque aún no hemos aprendido a dominarlo. Discutimos con sus autores porque aún no los hemos comprendido plenamente. Porque una obra canónica, como un clásico, no se termina nunca: “Clásico no es un libro (lo repito) que necesariamente posee tales o cuales méritos; es un libro que las generaciones de los hombres, urgidas por diversas razones, leen con previo fervor y con una misteriosa lealtad" (Borges $1975,616)$.

¿Se puede, entonces, establecer una relación fértil con el canon sin caer en el rezo o el escupitajo? En 1994, la prestigiosa revista The Monist publica un número dedicado al problema del canon en Filosofía y en disciplinas afines como la historia del arte. En su interior, encontramos un trabajo notable y muy sugerente del ya citado Richard Schacht quien, después de reconocer la importancia de Hegel para una correcta comprensión de las conexiones de entre Filosofía e Historia, afirma que es, sin embargo, Nietzsche el autor que más lejos y mejor ha pensado en esta dirección. En particular, Schacht encuentra de extraordinaria utilidad la segunda intempestiva del filólogo alemán para pensar en la riqueza y complejidad el problema del canon. Como es sabido, Nietzsche ensaya en este escrito tres modelos de aproximación a la Historia desde un horizonte teórico que se pregunta por las conexiones entre la ciencia y la vida y, sobre todo, por la posibilidad de poner la 
ciencia (la Filología, la Historia, la Filosofía) al servicio de la vida. Una ciencia que, lejos de atrofiar la línea ascendente de la gran salud, contribuya a su empuje, crecimiento y enriquecimiento. En un momento histórico marcado en Alemania por el auge académico de las Altertumswissenschaften y el positivismo, Nietzsche distingue tres tipos de Historia con el fin de denunciar sus ventajas e inconvenientes para la vida: monumental, anticuaria y crítica. Schacht se sirve de este esquema para pensar el problema que da título a su contribución: "On philosophy's canon, and its Nutzen und Nachteil" (Schacht 1993). Nos gustaría seguir la estela de este artículo para tratar de finalizar el nuestro.

Al igual que en el caso de la Historia para Nietzsche, Schacht cree que también es posible hablar del canon en sentido monumental, anticuario y crítico y que sólo este último, el crítico, está verdaderamente a la altura de una relación fértil, ágil y siempre renovada entre las ciencias y la vida. La apropiación que hace Schacht de la distinción nietzscheana nos sirve para ensayar una respuesta a la pregunta que hemos hecho más arriba: ¿es posible, hoy y siempre, con vistas al presente y al futuro de nuestras instituciones educativas, establecer una relación fértil e inteligente con el canon sin caer en el riesgo de la idolatría o el desprecio? Sin duda es posible. En primer lugar, los hechos: existe el canon filosófico; ese canon varía histórica y geográficamente con el paso del tiempo, es decir, es un canon flexible y abierto a modificaciones, si bien se impone en líneas generales en la tradición europea y su apertura al mundo latinoamericano; ese canon flexible es un hecho normativo, es decir, impone y regula qué debe ser estudiado principalmente por todos aquellos individuos que aspiren no tanto a una existencia filosófica en clave helenística como a una profesión en el terreno de la filosofía; el canon, por tanto, está ligado al poder político e institucional, a los procesos de designación de comités de expertos y al diseño, desde las autoridades pertinentes, de un catálogo de obras y autores que los estudiantes preuniversitarios y universitarios deberán manejar si quieren obtener sus títulos; a menos que miremos el presente con la perspectiva atribulada, ingenua y feliz del más inocente de los niños, parece imposible negar que esa dimensión política e institucional abre la puerta para que diversas influencias ideológicas jueguen un papel, si no determinante, al menos sí relevante en los procesos de formación del canon. La filosofía, en efecto, siempre ha estado al servicio del poder establecido o al de su cuestionamiento y, en este sentido, sería sencillo demostrar, como hace Moreño Pestaña en su brillante estudio, que el poder no es indiferente al tipo de saberes que se cultivan y promueven en un determinado sector espacio-temporal como la España franquista, la Iglesia Romana, el Estado prusiano o el reino de Francia. ¿Significa 
esto que las razones de fondo que hacen irrumpir a un autor u obra en el canon son puramente ideológicas? Parece claro que, junto a las posibles inercias ideológicas que sin duda convirtieron a Platón en el referente de una tradición que, al decir de Whitehead, puede ser entendida como un conjunto de comentarios a su obra, hay sin embargo, en ese mismo Platón, algo más que mero potencial ideológico. Hay un plus de fuerza. Ese plus tiene que ver, creemos, con aquello que convierte a la filosofía, hoy y siempre, en un ejercicio absolutamente necesario para alcanzar una vida buena, autónoma y merecedora de ser vivida. En Platón se conjugarían, de hecho, las dos fuerzas de las que hablábamos anteriormente citando a Bloom: la literaria y la filosófica. Belleza, exuberancia en la dicción, dominio de la metáfora, capacidad coral para construir historias y personajes. Junto a esa fuerza estética, la potencia dialéctica, el diálogo implacable, el ofrecer y refutar argumentos sin tregua, el rechazo a la aceptación ciega de tradición y los propios juicios, el juego constante de la crítica de uno mismo, de los demás, del mundo. El canon filosófico oficial bien puede estar viciado ideológicamente, pero eso no elimina las cualidades que convierten a buena parte de esas obras en auténticos monumentos de la cultura occidental: la originalidad, la fuerza argumentativa, el diálogo crítico constante con el presente y con el pasado. Siguiendo con las imágenes de Nietzsche y de Schacht, parece claro que el canon está lleno de ventajas. Probablemente, la más importante de todas ellas es que, en el caso de la Filosofía, el canon es siempre y necesariamente un objeto de disputa, de investigación y de confrontación, y nunca un objeto de fidelidad espiritual o un modelo de rectitud moral. El canon es nuestra esfinge. Pocos cánones tan irreverentemente combatidos como el nuestro.

¿Y las desventajas? Las desventajas son también innegables. Una perspectiva purista e intolerante sobre el canon puede conducir a nuestros estudiantes a una visión elitista, idealizada, colonial, clasista, racista y machista sobre la historia de pensamiento. Puede hacerlo porque, a poco que miremos, veremos que el canon filosófico occidental es un canon de varones blancos que, en muchos casos, han estado al servicio del poder establecido $y$, por tanto, en contra de las víctimas de dicho poder. No obstante, insisto, esa visión solo es peligrosa si creemos (religiosamente) en la mirada metafísica del purista en lugar de pensar (filosóficamente) la historia de la filosofía y la formación del canon como procesos no lineales complejos que, pese a cristalizar en normas, catálogos y listados venerables, tienen sentido en tanto que ficciones regulativas: realidades que operan, regulan y generan efectos, pero que no proceden metafísicamente de una esencia imperecedera, un plan providencial o un decurso natural del espíritu humano, sino del entramado entre acción racional y contexto situacional. No importa, en definitiva, 
qué es el canon, sino qué hacemos con él y contra él. No importa cuál es la naturaleza última del canon sino de qué modo lo instalamos en la educación filosófica que damos y recibimos: libro sagrado o esfinge; autor beatificado o dinosaurio; obediencia o ciencia.

Una última precisión: lo que importa en relación con el canon no es tanto lo que incluye como lo que excluye y por qué (dime de quién no hablas y te diré quién eres). Es conocido el silencio de Platón con respecto a Demócrito. El canon, como afirma Manzo, excluye porque selecciona y, en efecto, la exclusión, en sí misma, no es ni buena ni mala. Es más bien inevitable. No obstante, la potencia tóxica del canon tiene que ver con los procesos ideológicos de construcción de realidad mediante la creación, difusión y promoción de bienes culturales que apuntan o pueden apuntar a la defensa de valores como la intolerancia, el racismo, el fascismo, el clasismo o la xenofobia. Lamentablemente, el canon permite lecturas como éstas. Sin embargo, junto a ese peligro, como diría el poeta, crece a la vez la salvación, i.e., la responsabilidad crítica de la mirada que la filosofía debe arrojar siempre sobre sí misma. Sobre su pasado, su historia, sus cánones y su futuro incierto. Un hecho normativo pero flexible, decíamos con Westphal. Una pauta que, como la regla de medir de los arquitectos lesbios en la Ética a Nicómaco de Aristóteles, debe estar a la altura de adaptarse, doblarse, encogerse, avanzar, subir, retroceder. Volviendo a Nietzsche, podríamos ir un paso más allá en la línea de Schacht y recuperar para nuestro análisis no ya la segunda intempestiva, sino el enfoque genealogista de la crítica nietzscheana a la cultura moderna y la razón occidental. En concreto, recuperar tres figuras o tipos, tres momentos del análisis genealógico que se corresponden con tres fases de la investigación histórico-crítica sobre el valor de los valores morales. Tres niveles de profundización y radicalización en la mirada suspicaz dirigida a cualquier fenómeno cultural en general y al valor del canon en particular. En tres prólogos sucesivos de Humano, demasiado humano, Aurora y La gaya Ciencia, Nietzsche distingue tres momentos cruciales en la crítica genealógica y los identifica, sucesivamente, con "el espíritu libre", "el topo" y "el psicólogo". ${ }^{12}$ Como sabemos, el método genealógico no se pregunta por el ser de lo que es, sino por el origen, la procedencia y la historia de algo (una idea, un sentimiento, un valor, un constructo, un saber o un canon) que, si bien existe $\mathrm{y}$ es tenido por inmutable, respetado por incuestionable y venerado como absoluto, sin embargo, tiene el más infame e insignificante de los orígenes y pudo haber sido de un modo distinto al actual o no haber sido en absoluto.

12 Doy las gracias al profesor de la UAM (Madrid) José Emilio Esteban Enguita por llamarme la atención sobre este aspecto crucial de la genealogía nietzscheana. Para abundar en estas tres figuras, véase: Esteban, 2009, 261-291. 
El espíritu libre critica el error y el vacío sobre el que pivotan las creencias tradicionales de Occidente (el alma, el espíritu, la verdad, Dios, etc.). Por espíritu libre Nietzsche entenderá en Ecce homo y en el prólogo de Humano, demasiado humano el gesto crítico de rechazo no solo de las falsas creencias mentadas, sino también de aquellos valores supuestamente emancipadores del presente que, sin embargo, reproducen soterradamente los viejos ídolos del pasado (la Razón ilustrada o el factum moral kantiano son un buen ejemplo de ello) (Nietzsche, KSA, Bd. 2, 13-22). Por su parte, el topo socava esas creencias desenmascarando su sentido y su calidad de error interesado, representando un segundo nivel de profundidad en la crítica Nietzsche (KSA, Bd. 3, 12-17). Ya no se trata simplemente de liberarse de los viejos ídolos, de destruirlos y derrumbarlos. Ahora es necesario también desenmascararlos, i.e., comprender el sentido del fenómeno cultural como síntoma: ¿a qué responde el ídolo? ¿Al servicio de qué intereses emerge y se impone y en virtud de qué valores gobierna durante siglos? La crítica no se conforma, por tanto, con derribar negativamente al ídolo y denunciar su mendacidad, sino que aspira a comprender las razones de su éxito y su vigencia en la historia de Occidente (los trasmundos, por ejemplo, o el desprecio del cuerpo expresarían un miedo a la muerte que conduce a la negación de la vida en nombre de la eternidad). Por último, el psicólogo y el médico de la cultura representarían, tal y como sugiere el prólogo de La Gaya Ciencia, el momento culminante en la crítica de los valores (Nietzsche, KSA, Bd. 3, 345-352). El psicólogo es aquel que libera y desenmascara, pero sobre todo es aquel que interpreta todo fenómeno y todo síntoma desde el proyecto ético-político de la promoción de la salud y el desprecio de la enfermedad y la decadencia. Es decir, el momento psicológico del genealogista consiste en favorecer aquellos valores y fenómenos culturales que, lejos de potenciar el desprecio de la existencia en su crudeza trágica y en su fuerza, contribuyen a fortalecer la línea ascendente de la vida y el sentido de la tierra sin retroceder ante sus elementos más insoportables.

Quizás el canon filosófico de Occidente sea también un efecto de superficie. Un síntoma. Quizás debamos convivir con él y atravesarlo con la mirada triple del genealogista nietzscheano: reconociendo en su interior viejas formas de idolatría que en nada se avienen con el ejercicio filosófico y que, sin embargo, campan a sus anchas en nuestras ilustres universidades; desenmascarando el sentido -a menudo institucional y político, basado en el miedo y la pleitesía- de esas formas esclerotizadas de hagiografía; y, por último, experimentando, investigando y disfrutando el canon con el fin de poner nuestra ciencia filosófica al servicio de una vida mejor con nosotros mis- 
mos, en tanto que individuos, y con los otros, en tanto que ciudadanos. Criticar el canon para mejor comprender nuestro presente y para que sus más sonoras ausencias no dejen de perseguirnos como las Erinias al viejo Orestes. En última instancia, el canon es lo de menos y es lo de más. Lo de menos, siempre que se presente ante nosotros como un objeto digno de reverencia ciega y asunción acrítica. Lo de más, porque pone de manifiesto la fragilidad del quehacer filosófico y su distancia con respecto a toda pretendida neutralidad científica y toda verdad autoevidente ajena al universo del interés. El canon es lo de más porque evidencia una y otra vez, en cada discusión con la historia del pensamiento, que la filosofía es ante todo el despliegue de la potencia autocrítica de la razón, el compromiso exigente con la tradición y la renuncia innegociable a la inercia, la moda y el neón rutilante de las grandes estrellas del firmamento académico y catedralicio. Amicus canon, sed magis amica veritas. 


\section{BIBLIOGRAFIA}

Bloom, Harold. El canon de Occidente. Buenos Aires: Anagrama, 1995.

Borges, Jorge Luis. "Sobre los clásicos." En Otras inquisiciones, Obras Completas de Jorge Luis Borges. Madrid: Círculo de Lectores, 1975. pp. 615616.

Camus, Albert. El mito de Sísifo. Barcelona: Altaya, 1998.

Esteban, J. Emilio, "El espíritu libre, el topo y el psicólogo: figuras de la crítica y genealogía de la filosofía del porvenir" En ¿Nietzsche ha muerto? Memorias del Congreso Internacional, 2009, ed. De Gerardo Martínez y Julio Quesada: Universidad Veracruzana, Universidad Autónoma de Madrid y Fundación Hombre y Mundo, pp. 261-291.

González, María Cristina, y Nora Stigol. "La filosofía y su historia. Un debate abierto." Revista de Filosofía vol. 37, №2 (2012): 151-170.

Gracia, Jorge. "Cánones filosóficos y tradiciones filosóficas: El caso de la filosofía latinoamericana." Análisis filosófico vol. XXX, №1 (2010): 117134.

-. Latin-American Philosophy in the Twentieth Century: Man, Values and the Search for Philosophical Identity. New Tork: Prometheus Books, 1986.

-. Philosophy and Its History: Issues in Philosophical Historiography. New York: State University of New York Press, 1992.

—. "Hispanics, Philosophy and the Curriculum." Teaching Philosophy vol.22, №3 (1999): 241-248.

Jakobson, Jim. "Prolegomena to the Historiography of Philosophy." En The Past's Present. Essays on the Historicity of Philosophical Thinking, 2005, de Marcia Sá Cavalcante y Hans Ruin. Huddinge: Södertörn Philosophical Studies, pp. 55-93.

Manzo, Silvia. "Piezas de un modelo para armar, desarmar y rearmas. Autores, textos y temas en la construcción de cánones filosóficos." En La modernidad ayer y hoy, de Susana Maidana y María Risco. Tucumán: Universidad Nacional de Tucumán, 2017. 117-146.

Monterroso, Augusto. 1959. “El dinosaurio.” En Obras completas (y otros cuentos), de Augusto Monterroso. México DF: UNAM, 1959. P. 57.

Moreno Pestaña, José Luis. La norma de la filosofía. La configuración del patrón filosófico español tras la Guerra Civil. Madrid: Biblioteca Nueva, 2013.

Nietzsche, Friedrich. Sämtliche Werke. Kritische Studienausgabe in 15 Bänden. Hrsg. von Giorgio Colli und Mazzino Montinari. Berlin-New York: Walter de Gruyter Verlag, 1967-77. Neueausgabe 1999.

Onfray, Michel. La comunidad filosófica. Manifiesto por una Universidad popular. Barcelona: Gedisa, 2008.

-. Contra-historia de la filosofía. Barcelona: Anagrama, 2007.

—. Anti-manual de filosofía. Madrid: Alianza, 2005. 
Rabossi, Eduardo. En el comienzo Dios creó el canon. Biblia berolinensis. Buenas Aires: Gedisa, 2008.

Schacht, Richard. 1993. "On philosophy's canon, and its Nutzen und Nachteil.” The Monist vol. 76, №4 (1993): 421-435.

Spinoza, Baruch. Tratado teológico-político, traducido por A. Domínguez. Madrid: Altaya, 1986.

Westphal, Merold. "The Canon as Flexible, Normative Fact." The Monist vol. 76, №4 (1993): 436-449. 